\title{
Evidence of Contraception use among the Madrasha Teachers in a Selected Area of Dhaka City
}

\author{
Fatema Tania ${ }^{1}$, Nasrin Sultana ${ }^{2}$ \\ ${ }^{1}$ Senior Lecturer, Department of Applied Sociology, ASA University Bangladesh, Bangladesh \\ (taania_kh@yahoo.com) \\ ${ }^{2}$ Lecturer, Dept. of Public Health, ASA University Bangladesh, Bangladesh (nsultana20032003@yahoo.com)
}

Received 31 May, 2015

Copyright (C) 2014 (Kristina Khoo, Teoh Kok Ban, Chow Yong Neng, Beh Kok Hooi, Chong Yee Joan). This is an open access article distributed under the Creative Commons Attribution-NonCommercial-NoDerivatives 4.0 International License., which allowing others to download this work and share them with others as long as they credit us, but they can't change them in any way or use them commercially. In accordance of the Creative Commons Attribution License all Copyrights (C) 2014 are reserved for ABC Research Alert and the owner of the intellectual property (Kristina Khoo, Teoh Kok Ban, Chow Yong Neng, Beh Kok Hooi, Chong Yee Joan). All Copyright (C) 2014 are guarded by law and by $A B C$ Research Alert as a guardian.

\section{Abstract}

The population of Bangladesh is increasing in an alarming rate. To control this alarming population contraception use is essential. But contraception use depends on literacy, income, religion, cultural norms and surrounding environment. Most of the Bangladeshi people are illiterate and religious minded. Especially madrasha teachers have wrong notion to use contraception. This study aim to investigate the level of knowledge and the use of contraception among the madrasha teachers in a selected area of Mirpur in Dhaka city. It is a cross sectional study and a total number of 103 male teachers in selected madrasha were interviewed for conducting the research. This study finding shows that $45.63 \%$ respondents age were between 40-47 years, Mean age was 47 years of respondents and S.D is \pm 8.935 , Monthly income of the respondents $(51.46 \%)$ were in between $6,000-9,000$ taka, $58 \%$ of respondents family member were $4-6.28 .2 \%$ of the respondents has got the information about contraception method from TV, About $70.9 \%$ of the madrasha teacher had told that they use any type of contraception method, $74 \%$ had good knowledge about contraception method, $60.3 \%$ of them had told that they have faced economical problem to use, Among 73 respondents, $81 \%$ of them use the method as temporary and $19 \%$ of them use it as a permanently method. Among 73 respondents, $41.1 \%$ of them had told that they are satisfied by use of contraceptive method. Madrasha teachers are informing about contraception, but they have lack of proper knowledge and economic problem to use different methods.

\section{Keywords}

Contraception, Evidence, Knowledge, Method, Married Couple, Temporary and Permanent 


\section{Introduction}

In developing countries, the use of contraceptives is increasing and some countries like Bangladesh, Thailand and Indonesia have achieved notable success (Greenspan A., 1991). The selection of contraceptive methods depends on psychological, social and cultural factors (i.e. perceptions of contraception and existing social norms about this culture). More-over, the use of contraception is largely dependent on the knowledge and attitudes of males towards modern contra-caption (e.g. contraceptive pills, implants, inject able, intrauterine device, male and female condoms, vasectomy, tubal ligation etc.). The partner's disapproval of contraceptive use is associated with more use of traditional methods (e.g. coitus interrupts, periodic abstinence etc.). A study in Kenya showed that women whose partners disapproved the use of modern contraception were 1.15 times more likely to use traditional contraceptive methods. Another study in Bangladesh showed that couples who had more than four children were 2.29 times more likely to use modern contraceptives. Another study in Bangladesh found that married males, who had positive attitude towards modern contraceptives, were 3.98 times more likely to use any kinds of contraception (Kamal MM, 2013).

Bangladesh is a small country in Asia with a large population (149 million, 1035 people/sq. $\mathrm{km}$ ) and is ranked the seventh most populous country in the world. However, national family planning programs and non-government organizations in Bangladesh are playing an important role in the effort to lower the fertility rate and to increase prevalence of contraceptive use. Family planning programs in Bangladesh provide their services to households and not only provide information about modern contraceptive methods, but also distribute various forms of contraception in a house to house basis. The fertility rate in Bangladesh has decreased from 6.3 births per woman in the mid-1970s to 2.7 births in 2007, and the use of contraception has increased from $7.7 \%$ to $55.8 \%$ during the same period. (Rahman MD, 2011)

The prevalence of contraceptive use reached 61\% in Bangladesh in 2011. But the contraceptive prevalence rates are not the same in all areas of Bangladesh. The use of general contraceptives is lower (52\%) in rural areas compared to urban (60\%) areas. This shows that the social environment around people also influences the choice of contraceptive method. However, men can play an important role in reproductive decision making through their sexual, economic and social relationships. Most of the time, males make the decision of when to have a child, family size, when to stop childbirth, and what types of methods are used for the spacing of births (Olaitan OL. 2011).

The husband's approval of contraceptive use increase the contraceptive prevalence rates while disapproval leads to decrease the rate. Knowledge of contraception is playing a vital role in the use of different contraceptive methods. Males prefer to use the methods which they know about well, and those which are easily available to them. In Bangladesh, oral pills, injections and periodic abstinence are the most preferred methods but the rate of use of male centered methods (i.e. condoms and male sterilization) is very low (Kamal SMM. 2009).

People reject the use of contraceptives which are restricted by social norms. However, the choice of appropriate contraceptives is an important aspect of a couple's reproductive health. There is great deal of evidence in Bangladesh that males are more likely to use modern methods when they have already reached a desired family size (Magadi AM, 2003). 
Many studies have been carried out in Bangladesh about the determinants of family planning method choice in relation to various socio-demographic variables of women. But the role of the knowledge, attitude and approval of family planning of men has not been examined. So it is unknown how it affects a couple's choice of contraceptive method. .

Bangladesh is not exception to its population burden. The total population has been doubled from 75 million to about 150 million over the three and a half decades since its independence in 1971.Still Bangladesh is rural based country. The urban population has been growing very rapidly. Bangladesh has experienced dramatic increase of contraceptive use and a sensational decline in fertility over the three decades. This progress in population control program in Bangladesh has been well documented with testimony in home and abroad. Although the consecutive Demographic Health Surveys conducted in Bangladesh continually showed that the contraceptive prevalence rate (CPR) was higher in urban than rural areas, however, little is known on contraceptive use pattern among slum dwellers.

Contraception use is essential to control birth rate. But this practice is not sufficient among the madrasha teachers, because of their religious fundamentalism. In this study we try to assess the level of knowledge about contraception use among the madrasha teachers.

\section{Objectives}

General Objectives:

To assess the level of knowledge and practice of madrasha teachers about contraception Specific objectives:

- To describe the socio demographic characteristics of madrasha teachers.

- To explore the method of contraception used by the madrasha teachers.

\section{Literature Review}

To our knowledge, there is little evidence of the study on contraceptive use pattern among slum dwellers in Bangladesh. The studies conducted on fertility and contraceptive use are confined to micro level and DHS data and focused mainly on rural women or national level. Little attention has been paid on contraceptive behavior among slum dwellers, where $35 \%$ of the urban people of Bangladesh live. The principal contribution of this study is to driving up the understanding of contraceptive use and method choice among urban poor living in the slums using a nationally representative survey data conducted in 2006. The findings of the study reveal that, the overall CPR in the slum dwellers was $58.1 \%$. The prevalence of modern and traditional methods was $53.2 \%$ and $4.9 \%$ respectively. The overall prevalence of family planning method was $4.6 \%$ higher in the non-slum areas. The use rate of modern and traditional methods in the slum areas was lower by $2.4 \%$ and $2.2 \%$ respectively than non slum areas. In national level, the CPR was $55.8 \%$ in 2007, whereas the modern and traditional method use rate was $47.5 \%$ and $8.3 \%$ (NIPORT et al, 2009).

With regard to contraceptive method mix, oral pill was the most preferred method, followed by injectables and periodic abstinence. The preference of method mix among the study urban poor were in the line of national level as reported in the 2007 BDHS data. The responsibility of men in family planning was found negligible as it is evident that the rate of condom use and male sterilization was very low in the study population as compared to that of national 
level. The rate of female sterilization was also lower in the study urban poor women. The results suggest that older women were reluctant in contraceptive using than their younger counterparts. Although there was not found significant relationship between age and traditional method use, the younger women of prime reproductive age were significantly more likely to use modern methods than older women. This finding is consistent with those conducted in Bangladesh and other developing countries. (Barkat et al, 1997, Khan and Rahman, 1997)

NGO membership showed to have significant positive effect on contraceptive use and modern method preference. This finding is also consistent with an earlier study on Bangladeshi women (Amin et al, 1996). Participation in credit programs increases women's economic status and empowers women through the experience of group solidarity, increased mobility, access to information about modern contraceptive methods and services, and support from program staff. Moreover, women's involvement in credit programs increases their interaction outside of the home, relieving social isolation and exposing them to new role models and behaviors, the adoption of which are reinforced through group membership (Amin et al, 1996).

Women's work status is also an important determinant of contraceptive use as well as method choice. The increased likelihood of using any method and higher preference of both modern and traditional method for economically active women may be partly attributed to 'cost and benefit' of childbearing and childrearing. This finding supports the hypothesis that "childcare would seem to be a time-intensive activity that is not productive (in terms of earnings)and uses many hours that could be used at work which is earnings-intensive activity”(Becker, 1965).

A lack of knowledge of contraceptive methods or a source of supple, cost and poor accessibility are the barriers that exist in these countries. The health concerns of these individuals also stop a lot of women and men from using modern contraceptive methods. Side effects perceived or real are a major factor for the abandoning of the modern methods, unintended pregnancies leading to induced abortions are the major drawback in the vaginal methods, periodic abstinence and withdrawal. These methods have the least health concerns but have frequent contraceptive failures. Bruce (1995) estimate that the health concerns reduce prevalence on an average of 71 percent for the oral pills, 86 percent for IUCDs and 52 percent for sterilization. The users for contraceptive methods in the subcontinent come from different socio-economic groups and demographic subgroups within a country are highly segmented (Mabry RM, 2004).

Usually knowledge of contraceptive method refers to whether the respondent had heard of or knows of a family planning method. In the 1989 BFS, data on knowledge of family planning methods were collected through a series of questions by following what is popularly known as the "recall and prompting" procedure (WHS, 1980).

\section{Methodology}

The study design was cross-sectional study which was conducted to assess the level of knowledge and practice of madrasha teachers about contraception in a selected area of Mirpur, in Dhaka district. The target populations of the study were male teachers in selected madrasha of Mirpur area. The study duration was six months. The entire period will divide into different activities. A total of 103 male teachers in selected madrasha were interviewed for conducting the study. Data collection technique was by semi-structure questionnaire, which was incorporate items from both dependent and independent variables. 


\section{Findings of the Research}

Distribution of the respondent according to socio-demographic characteristics

Table 1: Distribution of the respondent according to age:

\begin{tabular}{|c|c|c|}
\hline Variables & Frequency(n) & Percentage \\
\hline Age & & \\
\hline 32-39 Years & 18 & 17.47 \\
\hline 40-47 Years & 43 & 45.63 \\
\hline 48-55 Years & 25 & 24.27 \\
\hline 56-63 Years & 09 & 8.73 \\
\hline 64-71 Years & 08 & 7.66 \\
\hline \multicolumn{3}{|c|}{ Mean age $47 \mathrm{SD} \pm \pm 8.935$} \\
\hline \multicolumn{3}{|l|}{ Monthly income (tk.) } \\
\hline No income & 14 & 13.6 \\
\hline $2,000-5,000$ & 29 & 28.16 \\
\hline $6,000-9,000$ & 53 & 51.46 \\
\hline $10,000-13,000$ & 7 & 6.78 \\
\hline \multicolumn{3}{|c|}{ Median income $8500 \mathrm{SD} \pm 4514.9$} \\
\hline Family member & & \\
\hline $1-3$ & 5 & 4.9 \\
\hline $4-6$ & 59 & 57.3 \\
\hline $7-10$ & 39 & 37.9 \\
\hline Number of children & & \\
\hline $1-2$ & 28 & 27.2 \\
\hline $3-4$ & 59 & 57.8 \\
\hline $5-6$ & 11 & 10.7 \\
\hline $7-8$ & 5 & 4.3 \\
\hline Age of last children (Years) & & \\
\hline $1-5$ & 22 & 21.2 \\
\hline $6-10$ & 37 & 35.6 \\
\hline $11-15$ & 28 & 27.3 \\
\hline $16-20$ & 15 & 14.1 \\
\hline Total & 103 & 100 \\
\hline
\end{tabular}

Among 103 respondents, $18(17.47 \%)$ teachers of madrasha were age between 32-25 years.43 (45.63\%) of the respondents were age between 40-47 years. most of the respondents belongs this group. $25(24.27 \%)$ of the respondents were age between 48-55 years. 09(8.73 $\%)$ of the respondents were age between 56-63 years and $08(7.66 \%)$ of the respondents were age between 64-71 years. Mean age was 47 years of respondents and S.D is \pm 8.935 . Monthly income of the respondents $(51.46 \%)$ were in between $6,000-9,000$ tk. $28.16 \%$ were in between 2,000-5,000tk.

This table shows that among 103 respondents, about $5 \%$ of the respondent's family member was 1-3 people. About 58\% of respondents family member were 4-6. Most of the respondents were belong in this size and about $38 \%$ of respondents family member were $7-10$. It is clear that $27.2 \%$ of the respondents had one or two children in their family. $57.8 \%$ of the respondents had three or four children in their family about $10.7 \%$ of the respondents had five or six children in their family and $4.3 \%$ of the respondents had seven or eight children in their family. Among 103 madrasha teacher, about $21.2 \%$ children/son of them age were between one to five years. About $35.6 \%$ children/son of them age were between six to ten years. 
$27.3 \%$ children/son of teacher age was between eleven to fifteen years old. $14.1 \%$ children/son of them age was between sixteen to twenty years old.

Figure 1: Distribution of the respondent according to desire of child $(n=103)$ :

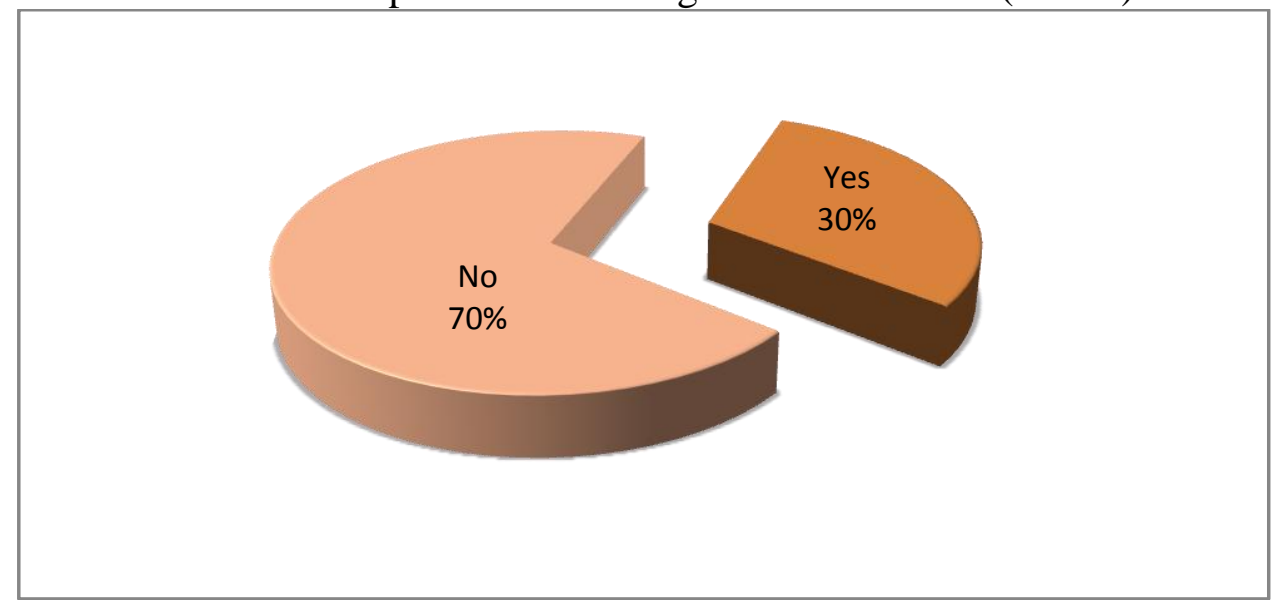

This figure shows that $70 \%$ of madrasha teacher had told that they had no intention to take any child more but $30 \%$ of madrasha teacher had intention to take one or more child.

Figure 2: Distribution of the respondent by source of information about contraception method $(n=103)$ :

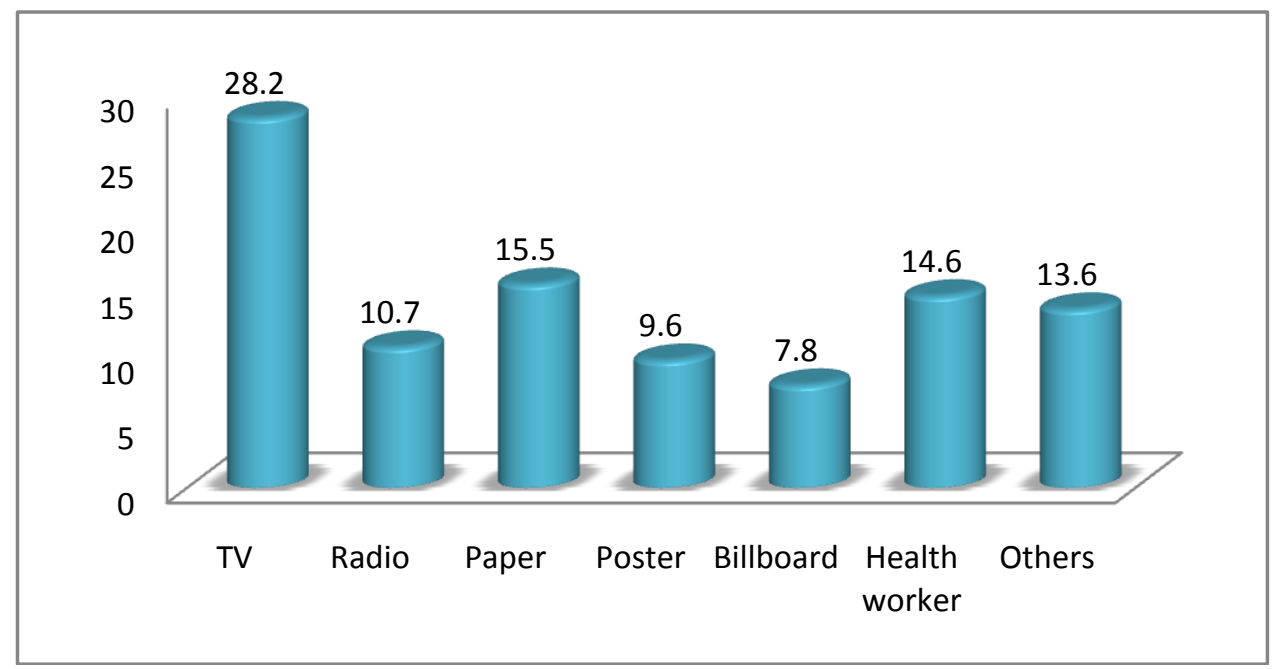

This figure state that about $28.2 \%$ of the respondents has got the information about contraception method from $\mathrm{TV}, 10.7 \%$ from radio, $15.5 \%$ from newspaper, about $9.6 \%$ from poster, $7.8 \%$ from billboard, $14.6 \%$ from health worker and $13.6 \%$ has got the information about contraception method from others sources. 
Table2: Distribution of the respondent by the knowledge about contraception method (103):

\begin{tabular}{|c|c|c|}
\hline $\begin{array}{ll}\text { Knowledge } & \begin{array}{l}\text { about contraception } \\
\text { method }\end{array}\end{array}$ & Number & Percentage(\%) \\
\hline Good & 76 & 73.79 \\
\hline Poor & 27 & 26.21 \\
\hline
\end{tabular}

Among 103 respondents, about 74\% had good knowledge about contraception method and about $26 \%$ of the madrasha teacher had poor knowledge about it.

Figure 3: Distribution of the respondent according to use of contraception method (103):

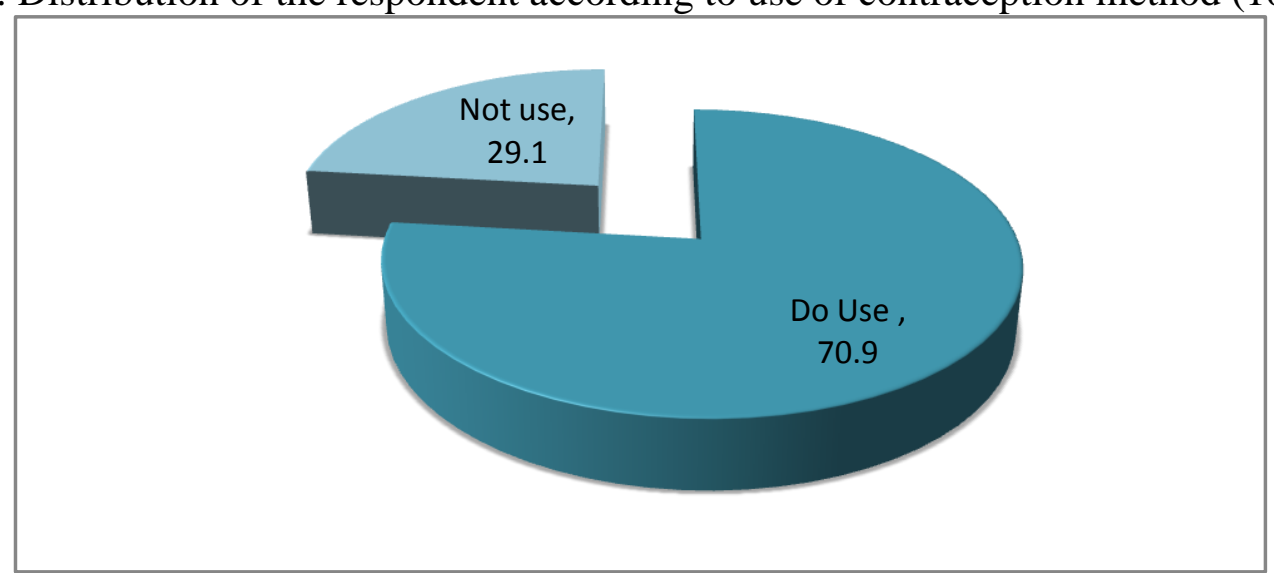

About $70.9 \%$ of the madrasha teacher had told that they use any type of contraception method and $29.1 \%$ of them don't use any type of method.

Figure 4: Distribution of the respondent according to using type of contraception method $(n=73)$ :

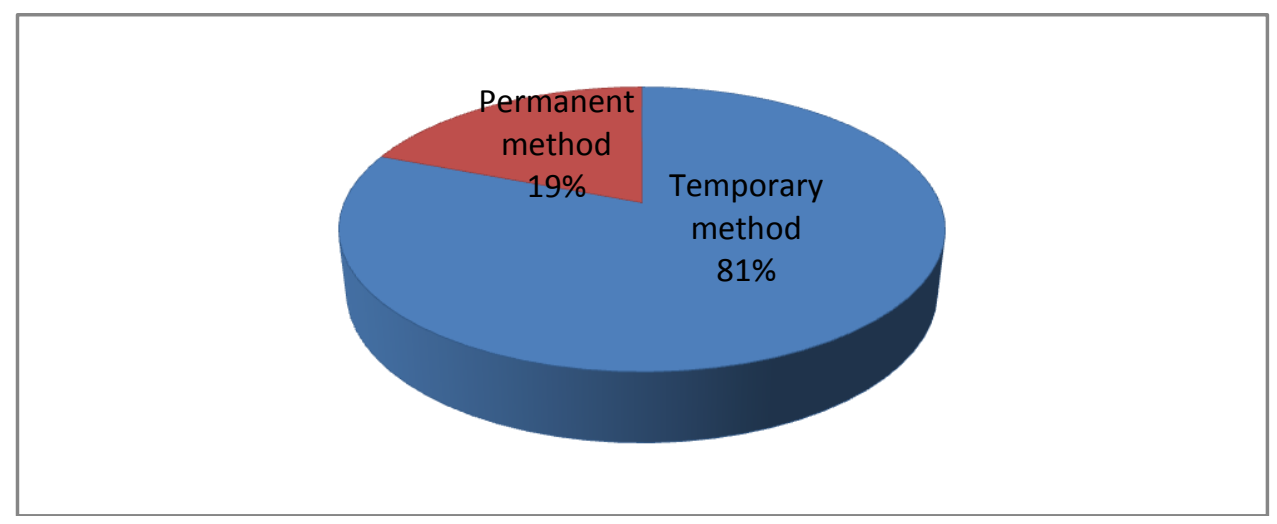

Among 73 respondents, $81 \%$ of them use the method as temporary and $19 \%$ of them use it as a permanently method. 
Figure 5: Distribution of the respondent according to permanent method which they use $(n=14)$ :

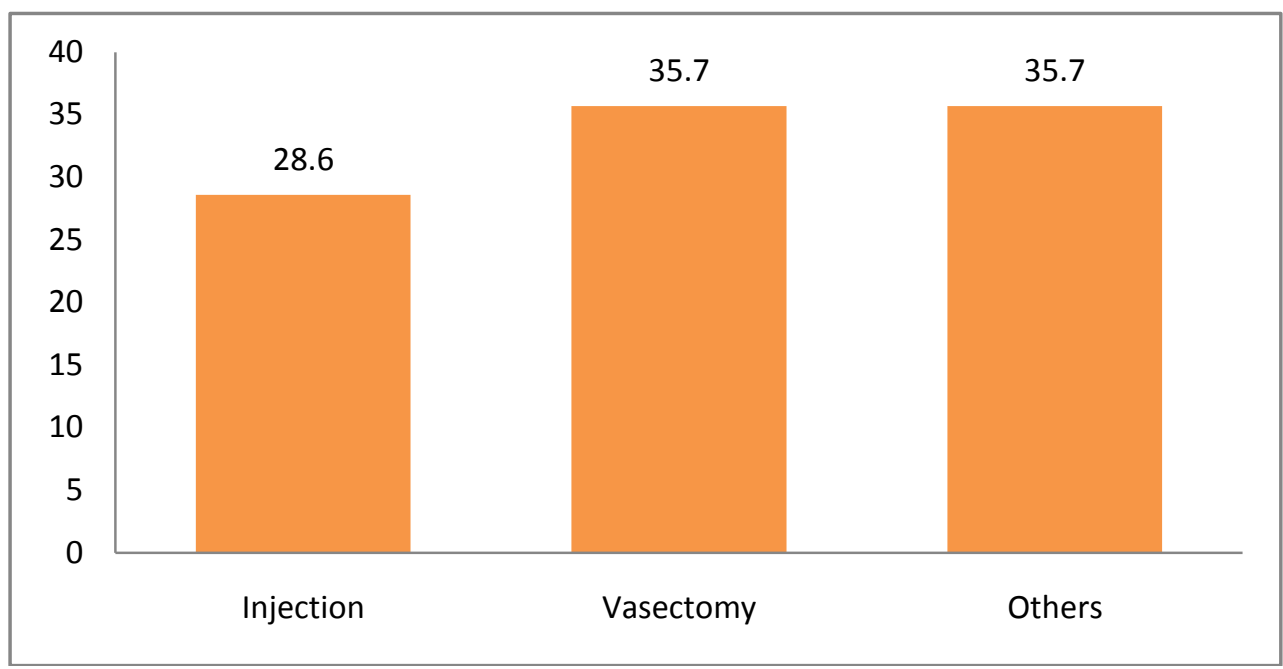

Among 14 study participants, 28.6\% of them had took injection as a permanent method, $35.7 \%$ of them had took vasectomy as a permanent method and $35.7 \%$ of them take others method.

Figure 6: Distribution of the respondent according to temporary method which they use $(n=59)$ :

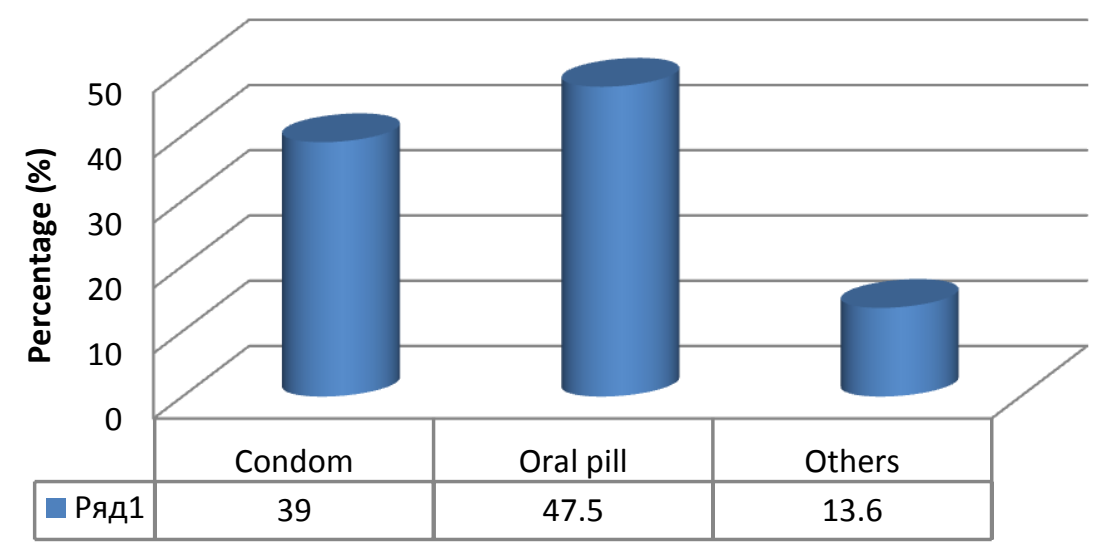

In this study, among 59 respondents, $39 \%$ had told that they use condom as a contraceptive method, $47.5 \%$ had told that they use oral pill as a contraceptive method and $13.6 \%$ had told that they use others method.

Table 3: Distribution of the respondent according to benefit by using contraceptive method $(n=68)$ :

\begin{tabular}{|l|l|l|}
\hline Benefited & Frequency & Percentage \\
\hline Physical & 22 & 32.4 \\
\hline Economical & 41 & 60.3 \\
\hline Others & 5 & 7.4 \\
\hline Total & $\mathbf{6 8}$ & $\mathbf{1 0 0}$ \\
\hline
\end{tabular}


Among 68 respondents, 32.4\% of them had told that they have got benefited by using any type of contraceptive method. $60.3 \%$ of them had told that they have faced economical problem to use it and $7.4 \%$ of them had told that they have faced other problems.

Table 4: Distribution of the respondent according to problem by using contraceptive method $(n=73)$ :

\begin{tabular}{|c|c|c|}
\hline Problem & Frequency & Percentage \\
\hline Yes & 25 & 34.2 \\
\hline No & 48 & 65.8 \\
\hline Total & $\mathbf{7 3}$ & $\mathbf{1 0 0}$ \\
\hline
\end{tabular}

Among 73 respondents, $34.2 \%$ of them had told that they have faced problem to use and $65.8 \%$ of them had told that they don't faced any problem.

Table 5: Distribution of the respondent according to satisfaction by using method $(n=73)$ :

\begin{tabular}{|l|l|l|}
\hline Satisfaction & Frequency & Percentage \\
\hline Yes & 30 & 41.1 \\
\hline Moderate & 26 & 35.6 \\
\hline No & 17 & 23.3 \\
\hline Total & $\mathbf{7 3}$ & $\mathbf{1 0 0}$ \\
\hline
\end{tabular}

Among 73 respondents, $41.1 \%$ of them had told that they are satisfied by use of contraceptive method, $35.6 \%$ of them had told that they satisfied moderately and $23.3 \%$ of them had told that they are not satisfied about it.

\section{Discussion}

Bangladesh is not exception to its population burden. Despite significant progress in family planning programme, the population of Bangladesh is increasing with an alarming rate. The total population has been doubled from 75 million to about 150 million over the three and a half decades since its independence in 1971. Though still Bangladesh is rural, over one-fourth of its total population is urban residents. The urban population has been growing very rapidly and continuous to do so at over $3.5 \%$ annually. The country will likely have an urban population approaching 50 million by 2015. This rapid growth has been due primarily to migration by the rural poor, particularly to slums and squatter settlements for shelter (CUB et al., 2006).

To know the level of knowledge and practice of contraceptive method among madrasha teacher in Mirpur area, we have conducted this descriptive cross sectional study. There are one hundred three madrasha teacher has participated to this research. Our study area was some selective madrasha in Mirpur area. The major finding was as follows:

Among 103 respondents, $18(17.47 \%)$ teachers of madrasha were age between 32-25 years.43 (45.63\%) of the respondents were age between 40-47 years. most of the respondents belongs this group.25 (24.27\%) of the respondents were age between 48-55 years. 09(8.73 $\%$ ) of the respondents were age between 56-63 years and $08(7.66 \%)$ of the respondents were age between 64-71 years. Mean age was 47 years of respondents and S.D is 8.935. Monthly family income was very common, maximum respondents income was between tk. 10000-15000 and most of them (74.8\%) live in their own home. 
In this study, it is clear that $27 \%$ of the respondents had one or two children in their family. $58 \%$ of the respondents had three or four children in their family about $11 \%$ of the respondents had five or six children in their family and $4 \%$ of the respondents had seven or eight children in their family. About $16 \%$ of the respondents had more than 5 children. Another interesting findings is about $30 \%$ of madrasha teacher had intention to take one or more child (Study report, 2014).

The practices of contraceptive method among madrasha teacher is very poor, Muslim religious leaders are often assumed to hold more conservative attitudes than the general population about family planning, yet a review of the literature finds no research that has specifically compared the two groups.

In this research, we found that, about $71 \%$ of the madrasha teacher had told that they use any type of contraception method and $21.4 \%$ of them don't use any type of method and Among 73 respondents, $81 \%$ of them use the method as temporary and $19 \%$ of them use it as a permanently method. In this study, among 103 respondents, $39 \%$ had told that they use condom as a contraceptive method, $47.5 \%$ had told that they use oral pill as a contraceptive method and $13.6 \%$ had told that they use others method (Study report, 2014).

\section{Conclusion}

Bangladesh is an over populated country. It seems unlikely that the change in method mix would negate the effect on fertility of a nine-point increase in CPR; thus, the effect of increased contraceptive use on fertility was probably counterbalanced by a reduction in the effect of one or more of the other proximate determinants on fertility. There has been no significant change in age at marriage or the proportion of married women in the country in recent years. On the other hand Muslim religious leaders are often assumed to hold more conservative attitudes than the general population about family planning, yet a review of the literature finds no research that has specifically compared the two groups. Indeed, Muslim religious leaders' stance toward family planning is often misinterpreted. While they can be expected to refer to religious texts for guidance as they seek to interpret the acceptability of new ideas, religious leaders may prove no more opposed than other members of society to innovation, unless a new idea is perceived to contravene religious tenets.

\section{Recommendations}

The study contains a number of implications for policy purposes that could be useful in devising ways to increase the contraceptive prevalence rate among madrasha teachers and thus bring about a further reduction in fertility in Bangladesh. These are as follows:

- Create awareness among madrasha teachers about social and economic consequences of early marriage, early pregnancy and large family size. This could be done through special information, education and communication (IEC) campaigns, regular home visits by family welfare visitors (FWVs) and family welfare assistants (FWAs).

- Proved madrasha teachers with information on the availability of family planning methods and their use-effectiveness.

- Improve the quality of care of reproductive health services and make them available at the door-step.

- Family planning, reproductive health education and other public health issue should be added on the madrasha curriculums. 


\section{References}

Al Riyami A, Afifi M, Mabry RM,(2004), Women's autonomy, education and employment in Oman and their influence on contraceptive use. Report Health Matters, 12:144-154.

Amin R, Li Y and Ahmed AU.(1996). Women's Credit Programs and Family Planning in Rural Bangladesh. International Family Planning Perspectives, 22: 158-162.

Barkat A, Rahman M and Bose ML (1997). Family Planning choice behavior in urban slums of Bangladesh: An econometric approach. Asia-Pacific Population Journal 12(1): 17-32.

Becker, Gary S. (1965), A theory of the allocation of time. The Economic Journal, 75 (299): 493-517.

Centre for Urban Studies (CUS), (2006). National Institute of Population Research and Training (NIPORT)

Greenspan A. (1991), Adding choice to the contraceptive Mix: Lessons from Indonesia, Asia Pacific Population Policy, No 19.

Gul, Y. (2014). Effect of Information Technology on Social Movements: A case study of Arab countries. Asian Journal Of Humanity, Art And Literature, 1(2), 84-96.

Jejeebhoy SJ, (1995), Women's education, autonomy and reproductive behavior: experience from developing countries Oxford, Clarendon Press.

Kamal MM, Islam MS, Jalil M. (2013), Determinants of current contraceptive use among married couples in Bangladesh: Views of males. Asian Profile; 42(2), 161-72

Kamal SMM.(2009), Contraceptive use and method choice in urban slum of Bangladesh. Conference paper, International Conference on Family Planning: Research and Best Practices, Kampala.

Khan MA and Rahman M. (1997), Determinants of contraceptive method choice in rural Bangladesh. Asia Pacific Population Journal 12(3): 65-82.

Magadi AM, Curtis LS. (2003,) Trends and determinants of contraceptive method choice in Kenya. Stud FamPlann; 34(3):149-59.

National Institute of Population Research and Training (NIPORT), MEASURE Evaluation, International Centre for Diarrhoeal Disease Research, Bangladesh (ICDDR, B) and Associates for Community and Population Research (ACPR) (2008)

Odumeru, J., \& Ilesanmi, O. (2015). The Effects of Human Resources Development on Financial Performance of Organisations. Asian Business Review, 2(1), 19-23.

Olaitan OL. (2011), Factors influencing the choice of family planning among couples in Southwest Nigeria.Int J Med MedSci ;3(7):227-32.

Perera, G., Khatibi, A., \& Navarathna, N. (2015). Relaionship between Employee-Organization Congruence (perceived) and Organizational Commitment in the Sri Lankan Apparel Sector. Asian Business Review, 1(2), 132-135.

Qamruzzaman, M., \& Ferdaous, J. (2015). Building a Knowledge-Based Economy in Bangladesh. Asian Business Review, 4(3), 41-49.

Rahman MD, Mondal MNI, Ali MK.( 2011), A study on the factors affecting the use of contraception in Bangladesh. Int Res J Biochem Bioinformatics;7:178-83.

Sadeghi, B., \& Safari, R. (2012). The Impact of Collaborative Task on the FL Vocabulary Acquisition. ABC Journal Of Advanced Research, 1(2), 8-14.

Sidi-Said, F. (2014). Domesticity as Gender Othering in Joseph Conrad's The Secret Agent. Asian Journal Of Humanity, Art And Literature, 1(1), 41-47.

Westoff CF and Rodríguez G. (1995). The Mass Media and Family Planning in Kenya. (International Family Planning Perspectives, $21: 26-31 \& 36$.

Zahan, N. (2014). Factors Influencing Women's Reproductive Health. ABC Journal Of Advanced Research, 3(2), 38-46. 